\title{
Controlled Surface-Assembly of Nanoscale Leaf-Type Cu-Oxide Electrocatalyst for High Activity Water Oxidation
}

\author{
Khurram S. Joya ${ }^{*},+\ddagger$ and Huub J. M. de Groot ${ }^{\dagger}$ \\ ${ }^{\dagger}$ Leiden Institute of Chemistry, Leiden University, Einsteinweg 55, P.O. Box 9502, 2300 RA Leiden, The Netherlands \\ ${ }^{\ddagger}$ Department of Chemistry, University of Engineering and Technology (UET), GT Road, 54890 Lahore, Punjab, Pakistan
}

\section{Supporting Information}

ABSTRACT: The controlled surface deposition of a robust and highperformance nanostructured copper-oxide $\left(\mathrm{CuO}_{\mathbf{x}}-\mathrm{NLs}\right)$ electrocatalyst for water oxidation is presented. The material exhibits a characteristic leaf-type morphology and self-assembles on a copper substrate by straightforward constant-current anodization. The oxygen onset occurs at about $1.55 \mathrm{~V}$ versus RHE $(\eta=320 \mathrm{mV})$, which is $400-500 \mathrm{mV}$ less than for amorphous Cu-oxide films. A Tafel slope of $44 \mathrm{mV} \mathrm{dec}{ }^{-1}$ is obtained, which is the lowest observed relative to other copper-based materials. Long-term catalytic performance and stability tests of the electrocatalytic $\mathrm{CuO}_{\mathbf{x}}$-NLs sample show a stable current density of $>17 \mathrm{~mA} \mathrm{~cm}^{-2}$ for oxygen evolution, which was sustained for many hours.

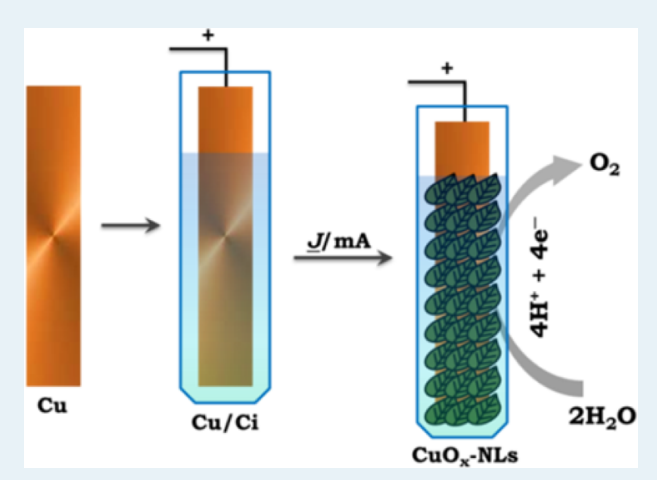

KEYWORDS: electrocatalyst, water oxidation, copper-oxide, nanoscale leaves, oxygen evolution

$\mathrm{T}$ here are continuous efforts to develop a strategy to produce renewable and cleaner energy carriers from abundant solar radiation and water. ${ }^{1,2}$ In this quest, catalytic water oxidation is regarded as a primary process, and many inorganic materials and transition metal-oxides are considered good candidates for this conversion. ${ }^{2,3}$ Metal-oxide catalysts can be electrodeposited on conducting substrates from carbonate, phosphate, or borate electrolytes in the presence of metal ions. $^{4-6}$ To eliminate the possibility for interaction of metal ions with the cathodic sites during electrolysis, membranes or separators are usually employed that make the system more complex and introduce resistance and diffusion limitations in the electrochemical process. ${ }^{7} \mathrm{New}$ preparation methods are required that are easily implemented, and catalytic materials are desired to perform in metal ion free systems for sustained electrochemical operation. 8 In addition, control over the catalyst morphology and surface structure is important to induce a high surface area and phase purity, facilitating both charge transfer and mass transport during catalysis reaction., ${ }^{9,10}$

Stable and efficient metal-oxide derived electrocatalysts can develop in a carbonate/bicarbonate system under mild conditions. ${ }^{5,11} \mathrm{HCO}_{3}{ }^{-} / \mathrm{CO}_{3}{ }^{2-}$ is suggested to facilitate proton management and prevent the degradation of these catalytic materials under anodic conditions. ${ }^{12-14}$ We observed that anodization of a copper electrode via repetitive potentialsweeps or at constant-potential in a carbonate buffer induces the formation of very small copper-oxide particulate materials $\left(\mathrm{CuO}_{\mathrm{x}}-\mathrm{NPs}\right)$ having oxygen onset at $\sim 1.59 \mathrm{~V}$ versus $\mathrm{RHE}(\eta \geq$ $360 \mathrm{mV}$ ). In addition, we found that nanoscale leaf-shaped $\mathrm{Cu}-$ oxide $\left(\mathrm{CuO}_{\mathbf{x}}-\mathrm{NLs}\right)$ surface structures (Figure S1) are formed during controlled anodization of a chemically etched copper substrate at a constant current density of $4.0 \mathrm{~mA} \mathrm{~cm}{ }^{-2}$ in a carbonate system. The $\mathrm{CuO}_{\mathbf{x}}-\mathrm{NLs}$ exhibit a remarkably low overpotential for water oxidation $(\eta=320 \mathrm{mV})$ relative to other $\mathrm{Cu}$-based electrocatalysts ${ }^{13-15}$ and many inorganic materials. $^{16,17}$

Scanning electron microscopy (SEM) imaging shows a leaves-type copper-oxide matrix (Figure 1a). Individual leaflets are around $250 \mathrm{~nm}$ long and $60-70 \mathrm{~nm}$ wide (Figure $1 \mathrm{~b}$ and S2). In contrast, copper oxide films produced by repetitive $\mathrm{CV}$ scans or via constant-potential surface anodization on native $\mathrm{Cu}$-foil reveal a particulate-type structural morphology (Figure 1c) with particle sizes around $70 \mathrm{~nm}$ (Figure 1d). We ascribe the uniform surface-generation of $\mathrm{CuO}_{\mathbf{x}}-\mathrm{NLs}$ on $\mathrm{Cu}$-substrate to a controlled surface electrochemical process involving $\mathrm{Cu}$ oxidation to form $\mathrm{Cu}^{n+}$ type surface species that quickly turn into a metal hydroxide/oxide type composition on the etched metal substrate during the metal-oxide deposition phase (Figure S3).

XPS (X-ray photoelectron spectroscopy) data are characteristic for $\mathrm{Cu}(\mathrm{II})$-oxides on a pure copper metal surface. The binding energy (BE) region between 928 and $965 \mathrm{eV}$ shows the response from the $\mathrm{Cu} 2 \mathrm{p}_{3 / 2}$ and $\mathrm{Cu} 2 \mathrm{p}_{1 / 2}$ core levels at 933.8 and $953.8 \mathrm{eV}$, respectively (Figure S4). ${ }^{18} \mathrm{~A}$ high BE of $933.8 \mathrm{eV}$ for the $\mathrm{Cu} 2 \mathrm{p}_{3 / 2}$ confirms the presence of $\mathrm{Cu}^{2+}$ species. ${ }^{19}$ The difference between the $\mathrm{Cu} 2 \mathrm{p}_{3 / 2}$ and $\mathrm{Cu} 2 \mathrm{p}_{1 / 2}$ levels is about 20 $\mathrm{eV}$, which is in good agreement with data for the spin-orbit splitting reported for $\mathrm{CuO}$ preparations. ${ }^{20}$ These observations

Received: December 25, 2015

Revised: February 10, 2016 

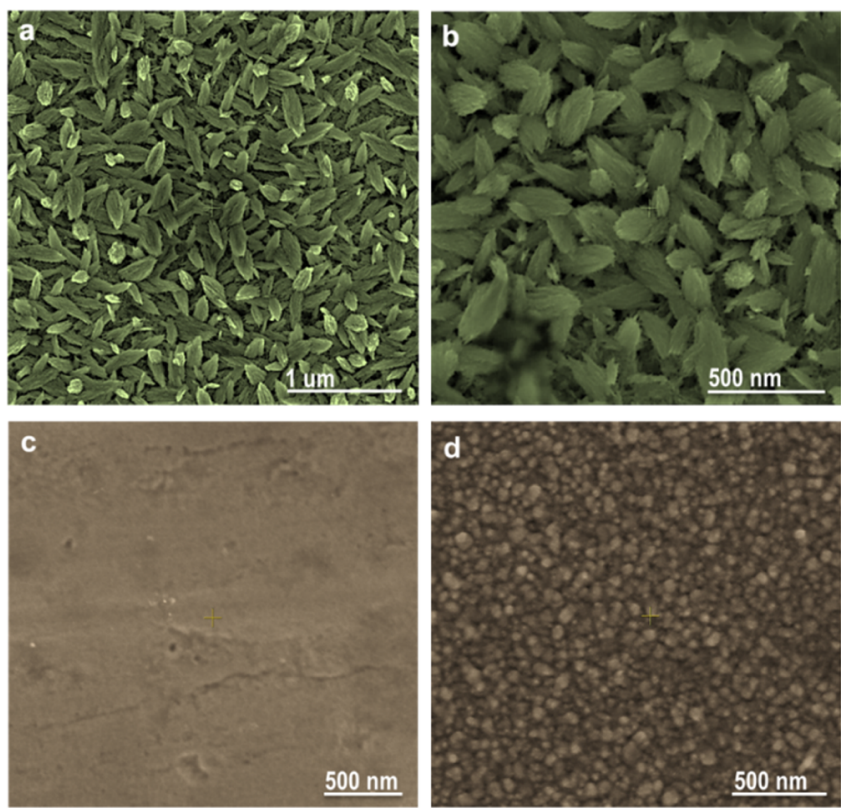

Figure 1. Scanning electron microscopy images for $(\mathrm{a}, \mathrm{b})$ the $\mathrm{CuO}_{\mathbf{x}}$ NLs samples; (c) the simple $\mathrm{Cu}$ foil and for (d) nanoparticulate copper-oxide film.

are representative XPS signatures of the presence of $\mathrm{Cu}$ (II) derived metal-oxides. ${ }^{21}$ Next to the $\mathrm{Cu} 2 \mathrm{p}_{3 / 2}$ XPS signal, there are two overlapping satellite peaks at higher BE between 940 and $943.9 \mathrm{eV}$ (Figure S4b). These satellite peaks are characteristic of $\mathrm{Cu}^{2+}$ materials with a $\mathrm{d} 9$ configuration in the ground state (absent in case of $\mathrm{Cu}_{2} \mathrm{O}$ ) and are in good agreement with the values reported for $\mathrm{Cu} 2 \mathrm{p}$ levels in $\mathrm{CuO}$ phase. ${ }^{22}$ The $\mathbf{C u O}_{\mathbf{x}}$-NLs sample exhibits a lattice $\mathrm{O} 1 \mathrm{~s}$ peak at binding energy of $531.8 \mathrm{eV}$ that is attributed to a surface-bound hydroxide species originating from adsorbed $\mathrm{H}_{2} \mathrm{O}$ molecules on the surface of the CuO-based film (Figure S4c). ${ }^{20}$

EDX (energy dispersive X-ray) measurements for the bulk elemental composition show $\mathrm{Cu}$ and $\mathrm{O}$ with a $1: 1$ ratio in the $\mathrm{CuO}_{\mathbf{x}}-\mathrm{NLs}$ film (Figure S5). There is about 9\% carbon content, which is thought to contribute to inducing high surface area, good electron transport, and enhanced structural flexibility. ${ }^{23}$ The Raman spectrum for the $\mathbf{C u O}_{\mathbf{x}}-\mathrm{NLs}$ reveals a $\mathbf{C u O}_{\mathbf{x}} \mathrm{Ag}$ band at approximately $295 \mathrm{~cm}^{-1}$ (Figure S6). The weak response at $340-344 \mathrm{~cm}^{-1}$ and a broad strong band centered at $628.5 \mathrm{~cm}^{-1}$ are assigned to the $2 \mathrm{Bg}$ modes in the metal-oxide. The Raman frequencies are well in line with data for pure single-phase $\mathrm{CuO}_{\mathbf{x}}$ films having good crystallinity. ${ }^{24}$

Cyclic voltammetry shows the onset of the catalytic water oxidation current at $1.55 \mathrm{~V}$ (vs RHE) that grows rapidly and reaches $>50 \mathrm{~mA} \mathrm{~cm}^{-2}$ under $1.84 \mathrm{~V}$ vs RHE (Figure 2). This $\mathrm{O}_{2}$ onset potential is the lowest reported for electrogenerated $\mathrm{Cu}$-oxide-derived water oxidation electrocatalysts. ${ }^{13,14}$ Extended potential sweeping to $2.1 \mathrm{~V}$ vs RHE strongly increases the current density, which approaches $200 \mathrm{~mA} \mathrm{~cm}{ }^{-2}$ on the $\mathrm{CuO}_{\mathbf{x}^{-}}$ NLs-based electrode surface (Figure S7). A magnified CV view shows a copper oxidation polarization prefeature between $0.7-$ $0.9 \mathrm{~V}$, followed by a small potential window of steady current and the pronounced catalytic wave at ca. $1.55 \mathrm{~V}$ (inset Figure 2 ). The oxidative prefeature can be attributed to the surface oxidation of metallic copper $\mathrm{Cu}^{0}$ into $\mathrm{Cu}^{\mathrm{I}}$, and leading to $\mathrm{Cu}^{\mathrm{II}}$ type species with potential increment. ${ }^{25,26}$

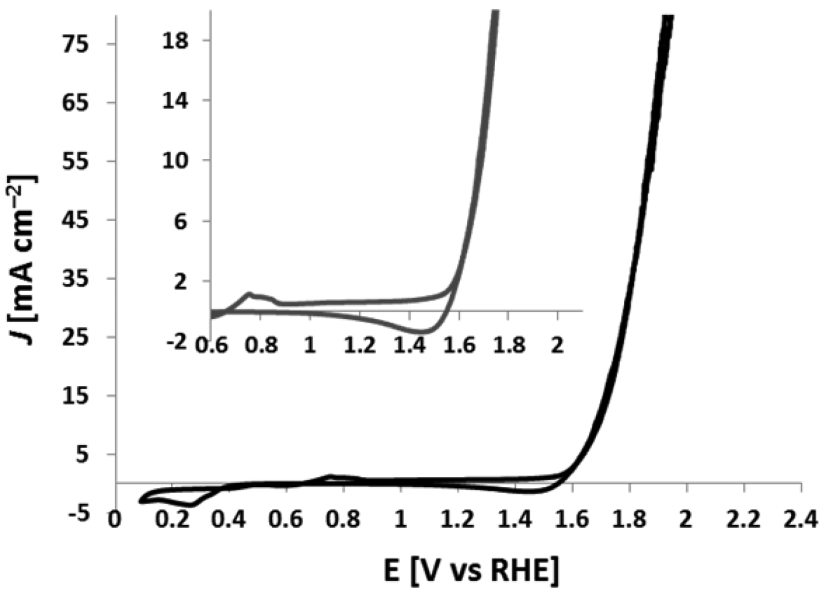

Figure 2. Cyclic voltammetry for the $\mathbf{C u O}_{\mathbf{x}}-\mathrm{NLs}$ electrocatalyst in 0.2 $\mathrm{M}$ carbonate buffer $(\mathrm{pH} \sim 11)$. Inset shows the magnified view of the CV $(0.6-2.1 \mathrm{~V})$.

The repetitive potential sweeps reproduce similar current density signatures on the 1st, 100th, and 500th CV scan, indicating little degradation or loss of performance of the $\mathrm{CuO}_{\mathbf{x}}$-NLs system during electrocatalysis (Figure 3). For the

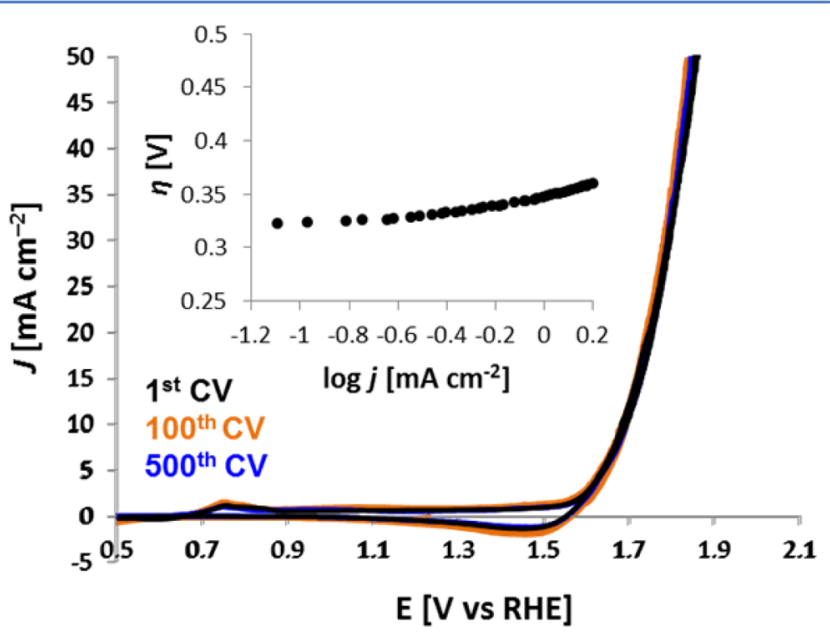

Figure 3. Concurrent 1st, 100th, and 500th $\mathrm{CV}$ sweeps for the $\mathrm{CuO}_{\mathbf{x}}$ NLs. Inset shows Tafel plot during oxygen evolution.

$\mathrm{Cu}$-oxide NPs type catalytic film, CV produces a higher $\mathrm{O}_{2}$ onset potential of $\sim 1.59 \mathrm{~V}$ (vs RHE), observed during water oxidation (Figure S8). Also there is relatively low catalytic activity of the $\mathrm{CuO}_{\mathbf{x}}-\mathrm{NPs}$ electrocatalyst compared to $\mathrm{CuO}_{\mathbf{x}}$ NLs in the higher potential regime and a current density of 50 $\mathrm{mA} \mathrm{cm}{ }^{-2}$ is obtained at $>2.0 \mathrm{~V}$ (vs RHE). The currentoverpotential ( $\eta$ vs log (i) plot of the $\mathrm{CuO}_{\mathbf{x}}-\mathrm{NLs}$ during OER produces a Tafel slope of $44 \mathrm{mV} \mathrm{dec}^{-1}$ (inset Figure 3). This Tafel slope is distinct for the $\mathbf{C u O}_{\mathbf{x}}-\mathrm{NLs}$ based electrocatalyst as the $\mathrm{CuO}_{\mathbf{x}}$-NPs presented here and other $\mathrm{Cu}$-oxide based electrocatalytic systems show much higher Tafel slopes (Figure S9). ${ }^{13,14,25}$ A small Tafel slope is representative of well-balanced kinetics over all steps of the entire conversion chain. The slow increase of the Tafel slope at higher voltages is attributed to increasing internal resistance. The system is characterized by high charge transfer rates, and a high density of active catalyst sites accumulated during anodic polarization. There is also good mass transfer from the open structural morphology and 
high crystallinity of the catalytic phase supporting electron transfer without scattering losses. ${ }^{9,23}$ In addition, the broad enhanced Raman response for the collective Bg mode at 629.5 $\mathrm{cm}^{-1}$ suggests the possibility for vibrationally assisted catalysis for avoiding transfer losses and potential drop in the catalytic sites when increasing the rate. ${ }^{27}$

For the long-term performance and stability test of the electrocatalytic $\mathrm{CuO}_{\mathbf{x}}$-NLs, controlled-potential water electrolysis (CPE) and controlled-current electrolysis (CCE) are conducted in carbonate electrolyte. CPE at $1.81 \mathrm{~V}(\eta \approx 580$ $\mathrm{mV}$ ) shows an excellent and sustained oxygen evolution current density approaching $17 \mathrm{~mA} \mathrm{~cm} \mathrm{~cm}^{-2}$ (Figure 4a). The current

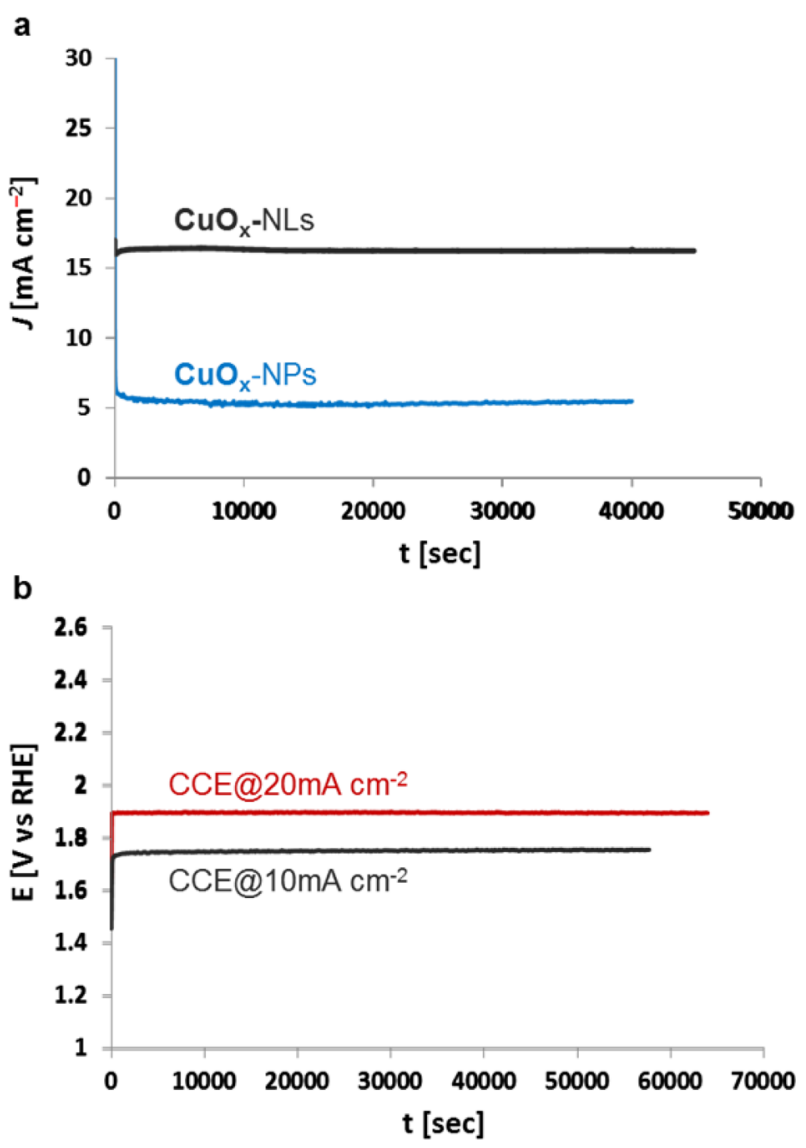

Figure 4. Extended period water oxidation during (a) controlled potential electrolysis using $\mathrm{CuO}_{\mathrm{x}}-\mathrm{NLs}$ and as-prepared $\mathrm{CuO}_{\mathrm{x}}-\mathrm{NPs}$ at $1.81 \mathrm{~V}$ vs RHE; and (b) constant current water electrolysis for the $\mathrm{CuO}_{\mathrm{x}}$-NLs based electrocatalyst at $J=10 \mathrm{~mA} \mathrm{~cm}^{-2}$ and $20 \mathrm{~mA} \mathrm{~cm}^{-2}$, in carbonate buffer.

density during $20 \mathrm{~h}$ remains highly stable with no noticeable decrease in catalytic performance. On the $\mathrm{CuO}_{\mathbf{x}}-\mathrm{NPs}$ system, the observed $\mathrm{O}_{2}$ evolution current density is $5.2 \mathrm{~mA} \mathrm{~cm} \mathrm{~cm}^{-2}$ during the CPE run. The current density for $\mathrm{CuO}_{\mathrm{x}}-\mathrm{NLs}$ layers is more than 3 times higher than for the $\mathbf{C u O}_{\mathbf{x}}-\mathrm{NPs}$ film (Figure 4a). For the $\mathrm{CuO}_{\mathbf{x}}-\mathrm{NLs}$ sample, online oxygen measurements show $955 \mu \mathrm{mol}$ of $\mathrm{O}_{2}$ generation in $10 \mathrm{~h}$ of CPE with a Faradaic efficiency of $>98 \%$, corresponding to an oxygen generation rate of $\sim 95.5 \mu \mathrm{mol}$ per hour, and about $39 \mu \mathrm{mol}$ of oxygen per hour for the as-prepared $\mathrm{CuO}_{\mathbf{x}}-\mathrm{NPs}$ (Figure S10).

During constant current electrolysis, the $\mathrm{CuO}_{\mathbf{x}}-\mathrm{NLs}$ sample remains remarkably stable for water oxidation at current densities of $10 \mathrm{~mA} \mathrm{~cm}^{-2}$ and $20 \mathrm{~mA} \mathrm{~cm}{ }^{-2}$. To achieve $10 \mathrm{~mA}$ $\mathrm{cm}^{-2}$, a very stable steady-state potential of $\sim 1.75 \mathrm{~V}$ (vs RHE) is preserved for more than $20 \mathrm{~h}$ of water electrolysis (Figure 4b). Similarly, a current density of $20 \mathrm{~mA} \mathrm{~cm}^{-2}$ is maintained at just $\sim 1.88 \mathrm{~V}$ (vs RHE) in a clean carbonate system. There is no observable catalytic degradation and change in the voltage during CCE, which is a direct indication of the stability and sustained catalytic activity of the $\mathrm{CuO}_{\mathbf{x}}$-NLs.

In summary, we have deposited a copper-oxide based electroactive material via controlled current anodization in a clean carbonate system $(\mathrm{pH} \approx 11)$ that forms a stable and highperformance water oxidation electrocatalyst. The $\mathrm{CuO}_{\mathbf{x}}-\mathrm{NLs}$ are crystalline, and no surface treatment, electrochemical conditioning, or pre/post- annealing procedures are required to develop them. Oxygen evolution initiates at a very low overpotential $(\eta=320 \mathrm{mV})$, and an oxygen evolution current density of $10 \mathrm{~mA} \mathrm{~cm}{ }^{-2}$ is achieved at $1.68 \mathrm{~V}$ (vs RHE). The current density remains stable during long-term testing for catalytic performance, and catalysis operation can be sustained for more than $24 \mathrm{~h}$. The high catalytic activity of the $\mathrm{CuO}_{\mathbf{x}}-\mathrm{NLs}$ electrocatalyst in carbonate solution is attributed to the leaftype convex nanostructured surface morphology, presence of carbon contents in the film, and the pure phase crystallinity with a characteristic vibrational structure of the collective $\mathrm{Bg}$ oxygen modes. Coupling of oxygen vibration to electronic charge transfer may facilitate catalysis and electron spin alignment for $\mathrm{O}-\mathrm{O}$ bond formation with the $\mathrm{Cu}$ in a d9 ground state. The high catalytic rate of the $\mathrm{CuO}_{\mathbf{x}}-\mathrm{NLs}$ system also confirms the synergistic role of the carbonate for electron transport in the catalytic cycle, while the strong catalytic response suggests a mediating role of the alkaline surrounding in the proton management. ${ }^{12}$ The high current density that can be achieved in this way is a step forward in the quest for solar to chemical energy conversion via water splitting. ${ }^{28,29}$

\section{ASSOCIATED CONTENT}

\section{S Supporting Information}

The Supporting Information is available free of charge on the ACS Publications website at DOI: 10.1021/acscatal.5b02950.

SEM, XPS, EDX, Raman spectra, and supporting electrochemical measurements and data (PDF)

\section{AUTHOR INFORMATION}

\section{Corresponding Author}

*E-mail: khurram_joya@uet.edu.pk.

Notes

The authors declare no competing financial interest.

\section{ACKNOWLEDGMENTS}

K.S.J. acknowledges research support from HEC-PAK and Leiden University/BioSolar Cells Program.

\section{REFERENCES}

(1) Smith, R. D. L.; Sporinova, B.; Fagan, R. D.; Trudel, S.; Berlinguette, C. P. Chem. Mater. 2014, 26, 1654-1659.

(2) Joya, K. S.; Morlanés, N.; Maloney, E.; Rodionov, V.; Takanabe, K. Chem. Commun. 2015, 51, 13481-13484.

(3) Dau, H.; Limberg, C.; Reier, T.; Risch, M.; Roggan, S.; Strasser, P. ChemCatChem 2010, 2, 724-761.

(4) Kanan, M. W.; Nocera, D. G. Science 2008, 321, 1072-1075.

(5) Joya, K. S.; Joya, Y. F.; de Groot, H. J. M. Adv. Energy Mater. 2014, 4, 1301929.

(6) Dincă, M.; Surendranath, Y.; Nocera, D. G. Proc. Natl. Acad. Sci. U. S. A. 2010, 107, 10337-10341. 
(7) Joya, K. S.; Vallés-Pardo, J. L.; Joya, Y. F.; Eisenmayer, T.; Thomas, B.; Buda, F.; de Groot, H. J. M. ChemPlusChem 2013, 78, 35-47.

(8) Schlögl, R. Angew. Chem., Int. Ed. 2015, 54, 3465-3520.

(9) Pickrahn, K. L.; Park, S. W.; Gorlin, Y.; Lee, H.-B.-R.; Jaramillo, T. F.; Bent, S. F. Adv. Energy Mater. 2012, 2, 1269-1277.

(10) Joya, K. S.; de Groot, H. J. M. ChemSusChem 2014, 7, 73-76.

(11) Joya, K. S.; Takanabe, K.; de Groot, H. J. M. Adv. Energy Mater.

2014, 4, 1400252.

(12) Koroidov, S.; Shevela, D.; Shutova, T.; Samuelsson, G.; Messinger, J. Proc. Natl. Acad. Sci. U. S. A. 2014, 111, 6299-6304.

(13) Yu, F.; Li, F.; Zhang, B.; Li, H.; Sun, L. ACS Catal. 2015, 5, 627-630.

(14) Du, J.; Chen, Z.; Ye, S.; Wiley, B. J.; Meyer, T. J. Angew. Chem., Int. Ed. 2015, 54, 2073-2078.

(15) Li, T.-T.; Cao, S.; Yang, C.; Chen, Y.; Lv, X.-J.; Fu, W.-F. Inorg. Chem. 2015, 54, 3061-3067.

(16) Young, E. R.; Nocera, D. G.; Bulovic, V. Energy Environ. Sci. 2010, 3, 1726-1728.

(17) Deng, X.; Tüysüz, H. ACS Catal. 2014, 4, 3701-3714.

(18) Wanger, C. D.; Riggs, W. M.; Davis, L. E.; Moulder, J. F.; Muilenberg, G. E. Handbook of X-Ray Photoelectron Spectroscopy: a reference book of standard data for use in $x$-ray photoelectron spectroscopy; PerkinElmer Corp., Physical Electronics Division: Eden Prairie, Minnesota, 1979; pp 80-82.

(19) Morales, J.; Sánchez, L.; Martín, F.; Ramos-Barrado, J. R.; Sánchez, M. Electrochim. Acta 2004, 49, 4589-4597.

(20) Devaraj, M.; Deivasigamani, R. K.; Jeyadevan, S. Colloids Surf., B 2013, 102, 554-561.

(21) Biesinger, M. C.; Lau, L. W. M.; Gerson, A. R.; Smart, R. S. C. Appl. Surf. Sci. 2010, 257, 887-898.

(22) Iijima, Y.; Niimura, N.; Hiraoka, K. Surf. Interface Anal. 1996, 24, 193-197.

(23) Mao, S.; Lu, G.; Chen, J. Nanoscale 2015, 7, 6924-6943.

(24) Lu, Y.; Qiu, K.; Zhang, D.; Lin, J.; Xu, J.; Liu, X.; Tang, C.; Kim, J.-K.; Luo, Y. RSC Adv. 2014, 4, 46814-46822.

(25) Chen, Z.; Meyer, T. J. Angew. Chem., Int. Ed. 2013, 52, 700-703.

(26) González, S.; Pérez, M.; Barrera, M.; González Elipe, A. R.; Souto, R. M. J. Phys. Chem. B 1998, 102, 5483-5489.

(27) Purchase, R. L.; de Groot, H. J. M. Interface Focus 2015, 5, 20150014.

(28) Joya, K. S.; Joya, Y. F.; Ocakoglu, K.; van de Krol, R. Angew. Chem. 2013, 125, 10618-10630; Angew. Chem., Int. Ed. 2013, 52, 10426-10437.

(29) De Respinis, M.; Joya, K. S.; de Groot, H. J. M.; D’souza, F.; Smith, W.; van de Krol, R.; Dam, B. J. Phys. Chem. C 2015, 119, 72757281. 